\title{
Genotipos del Gen Kappa-Caseína en Ganado Bovino Criollo del Distrito de Bambamarca, Cajamarca, Perú
}

\author{
Genotypes of Kappa-Casein Gen in Creole Cattle of Bambamarca District \\ (Cajamarca, Peru)
}

\author{
Marcos Almeyda R. ${ }^{1}$, Raúl Rosadio A. ${ }^{1}$, Lenin Maturrano H. ${ }^{1,2,3}$
}

\section{Resumen}

El presente estudio tuvo como objetivo determinar la frecuencia alélica y genotípica del gen kappa-caseína ( $\kappa-\mathrm{CN}$ ) en ganado bovino criollo. Se recolectaron 48 muestras de sangre de bovinos de nueve centros poblados del distrito de Bambamarca (Cajamarca, Perú). Se extrajo el ADN y la genotipificación se realizó mediante análisis de RFLP-PCR del gen $\kappa-C N$. Las frecuencias genotípicas encontradas fueron de 0.56, 0.27 y 0.17 para los genotipos $\mathrm{AB}, \mathrm{AA}$ y $\mathrm{BB}$, respectivamente, en tanto que las frecuencias alélicas resultaron ser de 0.552 y 0.448 para los alelos A y B, respectivamente. Se concluye que los animales evaluados presentan una baja proporción de individuos con el genotipo deseado BB, genotipo que favorece la producción de queso.

Palabras clave: bovino criollo, gen kappa-caseína, PCR-RFLP

\section{Abstract}

The aim of this study was to determine the allelic and genotypic frequency of kappacasein gene $(\kappa-\mathrm{CN})$ in creole cattle. For this purpose, 48 blood samples were collected from animals in nine villages of the Bambamarca district, Cajamarca, Peru. DNA was extracted and genotyping was performed by PCR-RFLP analysis of $\kappa-\mathrm{CN}$ gene. Genotype frequencies of $0.56,0.27$ and 0.17 for the $\mathrm{AB}, \mathrm{AA}$ and $\mathrm{BB}$ genotypes were found, while the allele frequencies were 0.552 and 0.448 for alleles $A$ and $B$ respectively. It was concluded that the tested group had a low proportion of individuals with the desired BB genotype that favors the production of cheese.

Key words: creole cattle, kappa casein gene, PCR-RFLP

${ }^{1}$ Sección de Biología y Genética Molecular, Laboratorio de Microbiología y Parasitología Veterinaria

${ }^{2}$ Laboratorio de Zootecnia y Producción Agropecuaria, Facultad de Medicina Veterinaria, Universi dad Nacional Mayor de San Marcos, Lima, Perú

${ }^{3}$ E-mail: lenin.maturrano@gmail.com

Recibido: 5 de noviembre de 2014

Aceptado para publicación: 6 de setiembre de 2015 


\section{INTRODUCCIÓN}

Los bovinos criollos del Perú representan un conjunto de poblaciones rústicas y heterogéneas, localmente adaptadas a las características difíciles del altiplano (Rivas et $a l ., 2007)$. Este tipo de ganado representa el $85 \%$ de la población nacional, y por sus características de rusticidad y adaptación a la altura son parte fundamental de la ganadería nacional (Rosemberg, 2002). Sin embargo, la actual política de desarrollo ganadero propone el incremento de la productividad a partir de la importación de reproductores con altos índices productivos; animales que no se encuentran adaptados a las condiciones ambientales de los Andes del Perú, lo cual provocaría un proceso de erosión genética con la probable pérdida de genes de resistencia y adaptación (Rivas et al., 2007).

Esta problemática impulsó que, en el 2003, el Instituto Nacional de Innovación Agraria (INIA), a través de la Dirección Nacional de Investigación en Recursos Genéticos, intentara realizar la caracterización morfométrica, productiva, bioquímica y molecular del bovino criollo en algunas zonas del país. No obstante, los estudios realizados no incluyeron cuencas lecheras de gran importancia en el país como aquella del departamento de Cajamarca, cuya producción de leche es destinada principalmente a la elaboración de queso.

La leche presenta una amplia gama de nutrientes y que en conjunto forman un sistema fisicoquímico relativamente estable (Badui, 1990). Las proteínas de la leche se dividen en dos grupos: las séricas ( $20 \%$ de la proteína total), y las caseínas ( $80 \%$ del total). El grupo de las caseínas está conformado por: $\alpha_{\mathrm{S} 1}$-caseína, $\alpha_{\mathrm{S} 2}$-caseína, $\beta$-caseína y la $\kappa$-caseína. Esta última constituye aproximadamente el $13 \%$ de las caseínas totales y es la proteína más estudiada, dado el rol que juega en la industrialización de la leche, especí- ficamente en la transformación de la leche en queso (Solarte et al., 2007).

Se han descrito dos variantes alélicas de la א-caseína: A y B. Los bovinos heredan de cada progenitor un alelo A o B conformando de esta forma los genotipos homocigotos AA o BB o el genotipo heterocigoto AB (Medrano y AguilarCórdova, 1990). Diversos estudios han demostrado que el genotipo BB presenta mayor proporción de $\kappa$-caseína y micelas más pequeñas, las cuales retienen más sólidos al momento de la coagulación para la producción de quesos, dando lugar a coágulos que contienen más grasas y menos agua y, por lo tanto, son más firmes para el procesamiento, mejorando el rendimiento del queso (Requena, 2007).

El genotipo de las proteínas lácteas puede determinarse a partir de distintos tipos de muestras para obtener el ADN y por distintas técnicas de genética molecular, dentro de las cuales se señala la técnica de Reacción en Cadena de la Polimerasa-Polimorfismo de la longitud del fragmento de restricción (PCR/ RFLP) (Uffo et al., 2006). La PCR/RFLP consiste en la amplificación molecular de una región del gen, seguida de la digestión con una enzima de restricción apropiada, permitiendo la visualización de los fragmentos en geles de agarosa (Clark, 1992). Con la PCRRFLP se puede identificar variantes alélicas de forma rápida en muestras de sangre de animales de cualquier sexo, edad o estado fisiológico, constituyendo una herramienta útil para la identificación de genotipos (Cervantes et al., 2007).

El presente trabajo buscó determinar las frecuencias alélicas y genotípicas del gen kappa-caseína $(\kappa-\mathrm{CN})$ en una muestra de ganado bovino criollo del distrito de Bambamarca, departamento de Cajamarca. Esta zona es la principal productora de queso en el norte del Perú (Infolactea, 2009). 
Cuadro 1. Concentración y volumen de los componentes de la mezcla estándar de PCR

\begin{tabular}{lccc}
\hline Compuesto & Concentración stock & $\begin{array}{c}\text { Concentración en la } \\
\text { mezcla estándar }\end{array}$ & $\begin{array}{c}\text { Volumen de la } \\
\text { mezcla estándar }\end{array}$ \\
\hline Multiplex PCR & - & - & $10 \mu \mathrm{l}$ \\
Master Mix 2X & $100 \mu \mathrm{M}$ & $10 \mu \mathrm{M}$ & $0.2 \mu 1$ \\
Cebador JK 3 & $100 \mu \mathrm{M}$ & $10 \mu \mathrm{M}$ & $0.2 \mu 1$ \\
Cebador JK 5 & - & - & $7.6 \mu 1$ \\
Agua & $50-100 \mathrm{ng} / \mu \mathrm{l}$ & $5-10 \mathrm{ng} / \mu \mathrm{l}$ & $2 \mu 1$ \\
ADN & & & $20 \mu \mathrm{l}$ \\
\hline Volumen final de & & & \\
mezcla estándar & & & \\
\hline
\end{tabular}

M ultiplex PCR M aster M ix 2X (QIAGEN \&): M gCl², dNTP, Buffer de PCR, Taq polimerasa y Q-Solution

\section{MATERIALES Y Métodos}

\section{Lugar de Estudio y Animales}

La colección de muestras se realizó en el mes de marzo de 2010 en nueve centros poblados del distrito de Bambamarca, provincia de Hualgayoc, departamento de Cajamarca. Los centros poblados fueron $\mathrm{La}$ Vizcacha, El Tambo, El Capulí, Pampa Grande, Maygasbamba, Cuñacales, San Antonio, Tallamac y Llaucán. La zona de estudio se encuentra ubicada a más de 2500 msnm.

Se recolectaron muestras de sangre de 48 bovinos criollos seleccionados al azar, no emparentados y sin distinción de sexo o edad. Las muestras de sangre se tomaron mediante punción de la vena yugular empleando tubos Vacutainer ${ }^{\circledR}$ de $3 \mathrm{ml}$ conteniendo $\mathrm{K} 2$ EDTA al 15\%. Las muestras fueron conservadas a $-20{ }^{\circ} \mathrm{C}$ y transportadas al laboratorio para su procesamiento.

\section{Análisis de las Muestras}

Para la extracción de ADN se utilizó un kit comercial (DNeasy ${ }^{\circledR}$ Blood \& Tissue Kit, QIAGEN $®)$, basado en la purificación de ADN en columnas con membrana de sílica. Con base a la secuencia de la proteína к-caseína, se amplificó un fragmento de 350 pares de base (pb). Para tal fin, se emplearon los cebadores JK5 y JK3 (Trujillo et al., 2000). Los componentes de la mezcla estándar de PCR y volumen final se muestran en el Cuadro 1.

Las condiciones empleadas para el PCR fueron: una etapa de desnaturalización inicial a $94{ }^{\circ} \mathrm{C}$ por $3 \mathrm{~min}$, seguido por 35 ciclos de desnaturalización $\left(94{ }^{\circ} \mathrm{C}\right.$ por $\left.45 \mathrm{~s}\right)$, hibridización $\left(63{ }^{\circ} \mathrm{C}\right.$ por $\left.1 \mathrm{~min}\right)$ y extensión $\left(72{ }^{\circ} \mathrm{C}\right.$ por $\left.1 \mathrm{~min}\right)$ y una extensión final a $72{ }^{\circ} \mathrm{C}$ por $10 \mathrm{~min}$.

Para la digestión del fragmento amplificado se utilizó $15 \mu 1$ del volumen de la reacción de PCR, al cual se le adicionó $0.6 \mu \mathrm{l}$ (10 $\mathrm{U} / \mu 1$ ) de enzima de restricción Hinf I, $2.25 \mu \mathrm{l}$ (10X) de Buffer B y $4.65 \mu 1$ de agua desionizada. Esta mezcla fue incubada durante $2 \mathrm{~h}$ a $37^{\circ} \mathrm{C}$ en baño maría. Los fragmentos digeridos fueron separados por electroforesis en gel de agarosa al $2 \%$ en buffer TBE $0.5 \mathrm{X}$ a $100 \mathrm{~V}$ por $2 \mathrm{~h}$. Para la visualización de los fragmentos, el gel fue teñido por inmersión en una solución de bromuro de etidio $(1 \mu \mathrm{g} / \mathrm{ml})$ y visualizado en un transiluminador UV. Para la estimación del tamaño de los amplicones se utilizó un marcador de peso molecular de $100 \mathrm{pb}$. 


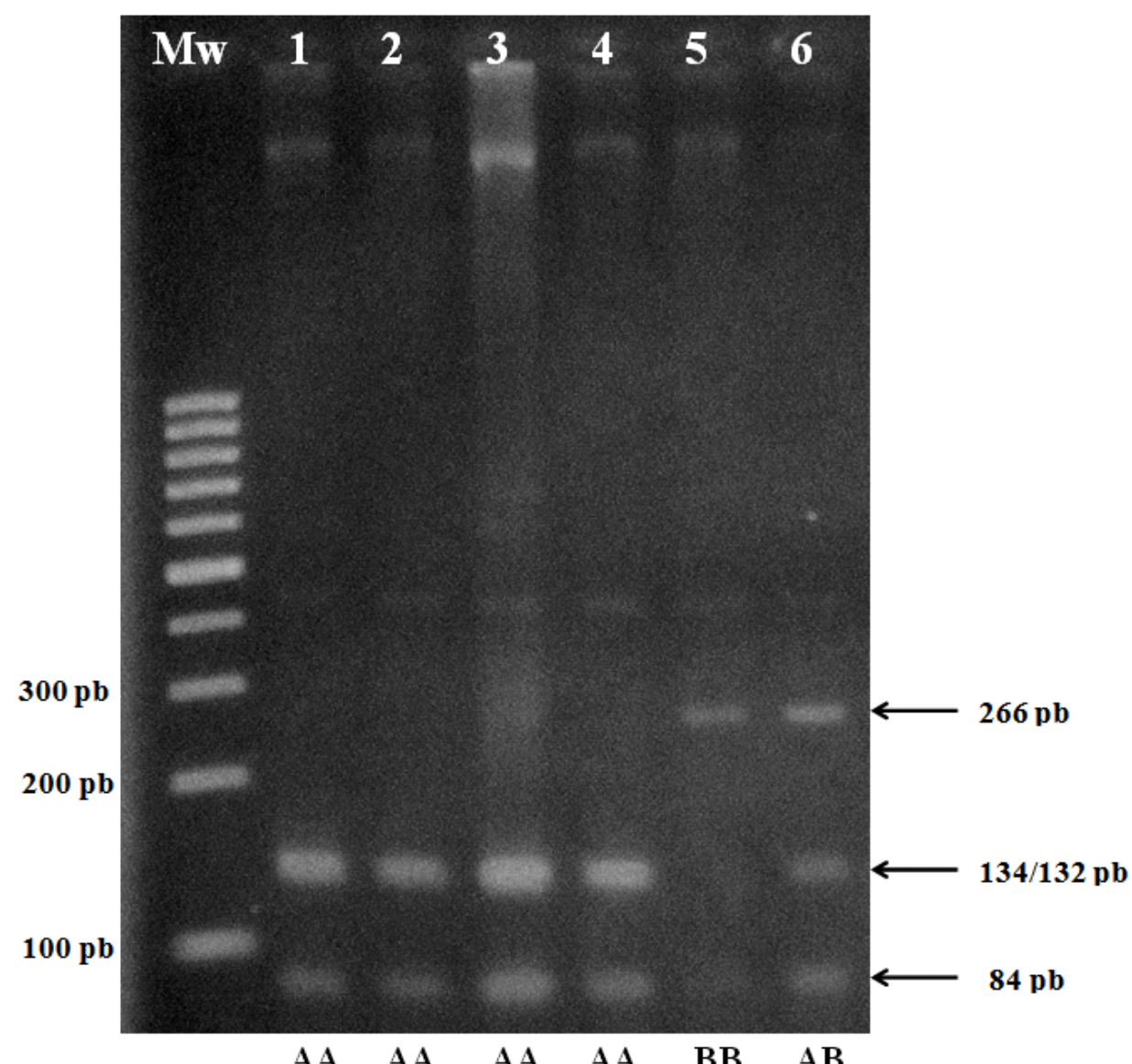

Figura 1. Reacción de restricción mostrando las variantes alélicas de la $\kappa$-caseína en geles de agarosa al 2\%. Mw: Marcador de peso molecular, carriles 1 a 4 corresponden a la forma homocigota $\mathrm{AA}$, carril 5 corresponde a la forma homocigota $\mathrm{BB}$ y carril 6 a la forma heterocigota $\mathrm{AB}$. El alelo A esta representado por los fragmentos de 134/132 y $84 \mathrm{pb}$, en tanto que el alelo B por los fragmentos de 266 y $84 \mathrm{pb}$

\section{Análisis de Resultados}

Se determinó el genotipo de los animales muestreados mediante recuento simple (conteo directo). Luego se procedió al cálculo de las frecuencias alélicas y genotípicas y, por último, se determinó si los animales muestreados estuvieron en equilibrio HardyWeinberg, mediante la prueba $\chi^{2}$ (Chi cuadrado), según la cual: $\chi^{2}=\Sigma(\mathrm{O}-\mathrm{E})^{2} / \mathrm{E}$, donde $\mathrm{O}=$ Número de individuos observados, $\mathrm{y}$ $\mathrm{E}=$ Número de individuos esperados.

\section{Resultados}

El producto amplificado por PCR correspondió a un fragmento de $350 \mathrm{pb}$ del gen de la $\kappa$-caseína del cromosoma 6 de bovino. Este fragmento amplificado digerido con la enzima de restricción Hinf I permitió la diferenciación genotípica del ganado bovino criollo. Para el genotipo AA se obtuvieron dos bandas, la primera compuesta por dos fragmentos de 134 y 132 pb y la segunda cons- 
Cuadro 2. Frecuencias genotípicas observadas y esperadas del gen de la $\kappa$-caseína en bovino criollo del distrito de Bambamarca

\begin{tabular}{ccccc}
\hline Genotipo & \multicolumn{2}{c}{ Observado } & \multicolumn{2}{c}{ Esperado } \\
\hline & $\begin{array}{c}\text { Frecuencias } \\
\text { Genotípicas }\end{array}$ & $\begin{array}{c}\text { Número de } \\
\text { individuos }\end{array}$ & $\begin{array}{c}\text { Frecuencias } \\
\text { Genotípicas }\end{array}$ & $\begin{array}{c}\text { Número de } \\
\text { individuos }\end{array}$ \\
\hline $\mathrm{AA}$ & 0.27 & 13 & 0.30 & 14 \\
$\mathrm{AB}$ & 0.56 & 27 & 0.50 & 24 \\
$\mathrm{BB}$ & 0.17 & 8 & 0.20 & 10 \\
\hline Total & 1 & 48 & 1 & 48 \\
\hline
\end{tabular}

Cuadro 3. Calculo del $\chi^{2}$ (Chi Cuadrado)

\begin{tabular}{cccc}
\hline Genotipo & $\begin{array}{c}\mathrm{N}^{\circ} \text { de individuos } \\
\text { observados }(\mathrm{O})\end{array}$ & $\begin{array}{c}\mathrm{N}^{\circ} \text { de individuos } \\
\text { esperados }(\mathrm{E})\end{array}$ & $(\mathrm{O}-\mathrm{E})^{2} / \mathrm{E}$ \\
\hline $\mathrm{AA}$ & 13 & 14 & $0 ., 071$ \\
$\mathrm{AB}$ & 27 & 24 & 0.375 \\
$\mathrm{BB}$ & 8 & 10 & 0.4 \\
\hline
\end{tabular}

$\chi^{2}=r(O-E)^{2} / E=0.071+0.375+0.4=0.846$

tituida por un único fragmento de $84 \mathrm{pb}$, para el genotipo BB se obtuvieron dos bandas de 266 y 84 pb y para el genotipo AB se obtuvieron tres bandas cuyos pesos moleculares fueron de 266, 134/132 y 84 pb (Fig. 1).

Las frecuencias genotípicas observadas correspondieron en un $56.3 \%(27 / 48)$ al genotipo $\mathrm{AB}, 27.0 \%$ (13/48) al genotipo $\mathrm{AA}$ y $16.7 \%(8 / 48)$ al genotipo BB. Asimismo, las frecuencias alélicas obtenidas fueron de $55.2 \%$ para el alelo A y de $44.8 \%$ para el alelo B. En base a las frecuencias alélicas se calcularon las frecuencias genotípicas esperadas y el número de individuos esperados (Cuadro 2).

Los animales muestreados se encontraron en equilibrio de Hardy Weinberg (no hay diferencia significativa entre los valores observados y esperados) con un valor de $\chi^{2}=$ 0.846 con 1 grado de libertad ( $p>0.05$ ) (Cuadro 3).

\section{Discusión}

Los genotipos de la $\kappa-\mathrm{CN}$ se relacionan con el contenido de caseína total de la leche, el cual a su vez se correlaciona con el rendimiento quesero (Van den Berg et al., 1992; Walsh et al., 1998). Si bien no se han realizado estudios sobre esta correlación en ganado bovino criollo, se presume que el gen de la $\kappa-$ CN ejercería los mismos efectos en el bovino criollo peruano, tal como se ha sugerido en algunos estudios sobre determinación de frecuencias alélicas y genotípicas de la $\kappa-\mathrm{CN}$ en ganado bovino criollo de otros países latinoamericanos (Poli et al., 2005; Uffo et al., 2006).

La aparente baja frecuencia del genotipo BB en los animales muestreados indicaría que la selección de estos animales ha ido favoreciendo al alelo A y, por consi- 
guiente, generando el incremento del número de animales con genotipo AA, posiblemente como consecuencia de endogamia o de selección de otra característica relacionada al rendimiento quesero, como la producción de litros de leche (Trujillo et al., 2000).

La frecuencia del alelo B en las muestras evaluadas resultó inferior a las frecuencias reportadas en el criollo venezolano (Rojas et al., 2009); similar a las encontradas en los criollos de Ancash (Rivas et al., 2007) y Junín (Veli y Rivas, 2010) en el Perú, y en los criollos uruguayo (Postiglioni et al., 2002) y tropical mexicano (Cervantes et al., 2007). Asimismo, superior a las frecuencias reportadas en el criollo argentino (Poli et al., 2005), colombiano (Naranjo et al., 2007), cubano (Uffo et al., 2006) y en los de Pampas de Lampa y Mesapampa, Ancash (Veli et al., 2004).

En estudios realizados en bovinos Jersey, raza cuya leche se caracteriza por su alto rendimiento quesero, se reporta una frecuencia superior al $77 \%$ del alelo B de la $\kappa$ CN (Grosclaude, 1988; González de Llano, 1990). Estos resultados al ser comparados con los obtenidos en el presente estudio podrían evidenciar que la leche del bovino criollo de Bambamarca posee en baja proporción el rasgo cuantitativo que favorece la manufactura quesera. Es posible que la baja frecuencia del alelo B pueda deberse a los programas de mejoramiento genético utilizados en la zona, con el empleo de inseminación artificial con semen de toros de razas importadas (Yanacocha, 2014), principalmente Holstein o Brown Swiss, caracterizadas por presentar una elevada frecuencia del alelo A del gen de la $\kappa-\mathrm{CN}$ (Formaggioni et al., 1999).

Los animales muestreados se encontraron en equilibrio Hardy-Weinberg $(\mathrm{H}-\mathrm{W})$, aunque este resultado podría estar afectado por el bajo número de muestras utilizado. De ser correcto el resultado, estaría indicando la no selección de animales en base al rendimiento quesero, el apareamiento de los ani- males en forma aleatoria, la ausencia de mutaciones en los individuos de la población o la no introducción de bovinos de raza importada (Lorenzano, 2008). Caso contrario, de no encontrarse en equilibrio, esto podría ser originado por la introducción de genes de ganado importado (generalmente a través de inseminación artificial), por la ocurrencia de apareamientos dirigidos o por el muestreo de animales emparentados (Cervantes et al., 2007). Por ello, sería necesario realizar estudios más amplios para confirmar la real situación del ganado de esta zona.

El kit para la extracción de ADN permitió una concentración de 50 a 100 ng/ $\mu 1$ de ADN. Otros estudios realizados en la misma especie (Trujillo et al., 2000; Naranjo et al., 2007; Rosero, 2009) utilizaron el método de extracción de Salting Out, el cual, a diferencia del kit empleado, requiere un mayor tiempo de acción por parte de la proteinasa K (1 a 3 horas, dependiendo del protocolo), lo que prolonga el tiempo total de la extracción de ADN (Villafañe y Posso, 2009; Riera et al., 2011).

La técnica de PCR-RFLP permitió determinar el genotipo de la $\kappa-\mathrm{CN}$ en todas las muestras (48/48), de manera similar a otros reportes (Trujillo et al., 2000; Darshan et al., 2008; Rojas et al., 2009) donde se utilizaron el mismo par de cebadores. Esta técnica muestra ventajas frente a otros métodos empleados para la selección de ganado como puede ser la prueba de progenie (evaluación del individuo en base a la producción de las hijas) (FAO, 1981; Ochoa, 1991) o el estudio del perfil electroforético de las proteínas lácteas (Vreeman et al., 1977). En el caso de las pruebas de progenie, seleccionar toros con el genotipo deseado $(\kappa-\mathrm{CN} \mathrm{BB})$ demandaría entre 6 y 7 años (Medrano y Aguilar-Córdova, 1990; Azevedo et al., 2008), lo cual hace poco práctico establecer programas de selección conducentes a incrementar la frecuencia génica del alelo deseado en la población. Asimismo, la caracterización genotípica en base a la realización de perfiles electroforéticos de las proteínas de la leche 
solamente puede realizarse en hembras en periodos de lactancia (Felmer y Butendieck, 1998).

El lugar de muestreo destaca por su elevada producción de derivados lácteos, esencialmente de queso (MINAG, 2009). Este aspecto es el que diferencia el presente estudio de otros realizados en el país por INIA en Ancash, Ayacucho y Junín (Veli et al., 2004; Rivas et al., 2007; Veli y Rivas, 2010), departamentos que a diferencia de Cajamarca no destacan por ser cuencas lecheras (Santa Cruz et al., 2006).

\section{Conclusiones}

$\mathrm{El}$ genotipo $\mathrm{AB}$ de la $\kappa-\mathrm{CN}$ fue el más frecuente $(56.3 \%)$ y el alelo A de la $\kappa-\mathrm{CN}$ el más elevado (55.2 \%) en el bovino criollo de Bambamarca.

\section{Agradecimientos}

Los autores agradecen a los pobladores del distrito de Bambamarca, Cajamarca, que colaboraron en el estudio. Un especial agradecimiento a la familia Benavides Idrogo por el apoyo logístico y las facilidades brindadas durante el muestreo.

\section{Literatura Citada}

1. Azevedo A, Nascimento C, Steinberg $R$, Carvalho M, Peixoto M, Teodoro $\boldsymbol{R}$, Verneque $R$, et al. 2008. Genetic polymorphism of the kappa-casein gene in Brazilian cattle. Genet Mol Res 7: 623630. doi: $10.1590 / \mathrm{S} 1415-4757200500$ 0100014

2. Badui S. 1990. Química de los alimentos. $2^{\mathrm{a}}$ ed. México: Alhambra Mexicana. $648 \mathrm{p}$.

3. Clark A. 1992. Prospects for the genetic engineering of milk. J Cell Biochem 49: 121-127. doi: 10.1002/jcb.240490204
4. Cervantes P, Luna M, Hernández A, Pérez-Gil F, Ponce P, Uffo O. 2007. Polimorfismo genético en el locus de la kappa-caseína, en vacas de diferentes razas y cruces en el trópico mexicano. Rev Salud Anim 29: 78-84.

5. Darshan R, Swathi S, Govindaiah M, Nagaraja $C$, Byregowda $S$, Jayashankar M. 2008. Molecular characterization of kappa-casein gene in buffaloes. Science Asia 34: 435-439. doi: $10.2306 / \mathrm{scienceasia} 1513$ 1874.2008.34.435

6. [FAO] Organización de las Naciones Unidas para la Agricultura y la Alimentación. 1981. Recursos genéticos animales en América Latina. Roma: FAO. Estudio FAO: Producción y Sanidad Animal. $170 \mathrm{p}$.

7. Felmer R. Butendieck M. 1998. Frecuencia alélica del gen de la k-caseína bovina en un rebaño Frisón Negro Chileno. Arch Med 30: 145-150.

8. Formaggioni $P$, Summer $A$, Malacarne M, Mariani P. 1999. Milk protein polymorphism: detection and diffusion of the genetic variants in Bos genus. Università Degli Studi Di Parma [Internet]. Disponible en: http:// www.betacasein.net/Formaggioni_ et_al,_1999.pdf

9. González de Llano D. 1990. Polimorfismo genético de las proteínas de la leche de vaca. Alimentación, Equipos y Tecnología 6: 77-81.

10. Grosclaude F. 1988. Le polymorphisme génétique des principales lactoprotéines bovines. Relarions avec la quantité, la composicion et les aptudes fromagères du lait. INRA Prod Anim 1: 5-17.

11. Infolactea. 2009. 170 toneladas semanales de quesos se producen en Bambamarca. [Internet]. Disponible en: http://www.infolactea.com/ noticias_detail.php?not_id=379\&tp_id=3

12. Lorenzano P. 2008. Bas Van Fraassen y la ley de Hardy-Weinberg: una discusión y desarrollo de su diagnóstico. Principia 12: $121-154$. doi: $10.5007 / 1808$ 1711.2008v12n2p121 
13. Medrano J, Aguilar-Córdova E. 1990. Genotyping of bovine kappa-casein loci following DNA sequence amplification. Biotechnology 8: 144-146. doi: 10.1038/ nbt0290-144

14. [MINAG] Ministerio de Agricultura. 2009. Boletín de leche - Cajamarca. [Internet]. Disponible en: http:// www.minag.gob.pe/portal/download/ $\mathrm{pdf} /$ herramientas/boletines/boletinleche2009.pdf

15. Naranjo J, Posso A, Cardenas H, Muñoz J. 2007. Detección de variantes alélicas de la kappa-caseína en bovinos Hartón del Valle. Acta Agronómica 56(1): 43-47.

16. Ochoa P. 1991. Mejoramiento genético del ganado bovino productor de leche. Cienc Vet 5: 67-88.

17. Poli M, Holgado F, Rabasa A. 2005. Frecuencias genotípicas y alélicas de los genes de CSN3 y lactoglobulina B en un rodeo de bovinos Criollos en Argentina. Veterinaria (Montevideo) 40: 44-48.

18. Postiglioni A, Rincon G, Kelly L, Llambi S, Fernández $G$, $D$ Angelo $M$, Gagliardi G, et al. 2002. Biodiversidad genética en bovinos criollos del Uruguay. Análisis con marcadores moleculares. Arch Zootec 51: 195-202.

19. Requena F. 2007. Genética de la caseína de la leche en el bovino Frisón. REDVET 8(1). [Internet]. Disponible en: http://www.veterinaria.org/revistas/ redvet/n010107/010702.pdf

20. Riera M, Rojas M, Zapata P. 2011. Protocolo de extracción de DNA por Salting-out para pequeños volúmenes de sangre. Rev Cienc Tecnol 14: 4-7.

21. Rivas E, Veli E, Aquino Y, Rivas V, Pastor S, Estrada R. 2007. Acciones para la caracterización y conservación del bovino criollo peruano (Bos taurus). AGRI 40: 33-42.

22. Rojas I, Aranguren-Méndez J, Portillo M, Villasmil-Ontiveros $Y$, Valbuena E, Rincón X, et al. 2009. Polimorfismo genético de la kappa-caseína en ganado criollo Limonero. Rev Cient (Maracaibo) 19: 645-649.
23. Rosemberg M. 2002. Variabilidad genética de vacunos criollos y de doble propósito. En: I Congreso Peruano de Genética Animal. Lima, Perú.

24. Rosero J. 2009. Polimorfismo de los genes k-caseína, $\beta$-lactoglobulina y $\alpha$ lactoalbúmina en razas bovinas criollas colombianas. Tesis de Maestría. Colombia: Univ Nacional de Colombia. 105 p.

25. Santa Cruz V, Sánchez M, Pezo S. 2006. Análisis de la cadena productiva de lácteos Cajamarca. [CODELAC] Coordinadora del Sector de Derivados Lácteos de Cajamarca. [Internet]. Disponible en: http://www.infolactea.com/ descargas/biblioteca/218.pdf

26. Solarte C, Burgos W, Martínez A, Zambrano G, Erazo M. 2007. Importancia de la determinación del genotipo de la kappa-caseína en la industrialización láctea. Infórmese Colácteos 11(1): 4-8.

27. Trujillo E, Noriega D, Camargo M. 2000. Genotipificación de kappa-caseína bovina y evaluación de las frecuencias genotípicas y alélicas de sus polimorfismos en cuatro razas. Actual Biol 22: 145-152.

28. Uffo O, Martín-Burriel I, Martínez S, Ronda R, Osta R, Rodellar C, Zaragoza P. 2006. Caracterización genética de seis proteínas lácteas en tres razas bovinas cubanas. Anim Genet Resource Inf 39: 15-24. doi: 10.1017/S1014233900 002108

29. Van den Berg G, Escher J, De Koning P, Bovenhuis H. 1992. Genetic polymorphism of kappa-casein and betalactoglobulin in relation to milk composition and processing properties. Neth Milk Dairy J 46: 145-168.

30. Veli E, Rivas V, Rivas E, Gutiérrez, G, Pastor S, Altamirano S. 2004. Estudio preliminar de la variabilidad genética del gen de kappa caseína en bovinos criollos de la CC Qochapunco, Ayacucho. En: V Simposio Iberoamericano sobre la conservación y utilización de recursos zoogenéticos. UNA, Puno, Perú. 
31. Veli E, Rivas E. 2010. Caracterización genética de kappa caseínas y betalactoglobulinas del bovino criollo de cuatro comunidades andinas del Perú. Anim Genet Resources 46: 67-72. doi: 10.1017/ S2078633610000718

32. Villafañe C, Posso D. 2009. Protocolos de extracción de ADN total de animales método de Salting Out. Protocolos de laboratorio UEG [Internet]. Disponible en: http://www.ivic.gob.ve/ ecologia/ueg/

33. Vreeman H, Both P, Brinkhuis J, Van der Spek C. 1977. Purification and some physicochemical properties of bovine $\kappa$ - casein. Biochim Biophys Acta 491: 93-103.

34. Walsh C, Guinee T, Reville W, Harrington D, Murphy J, O'Kennedy $B$, Fitzgerald R. 1998. Influence of kappa-casein genetic variant on rennet gel microstructure, cheddar cheesemaking properties and casein micelle size. Int. Dairy J 8: 707-714. doi: 10.1016/ S0958-6946(98)00103-4

35. Yanacocha. 2014. Proyectos productivos impulsan zonas rurales de Cajamarca. [Internet]. Disponible en: http://www.yanacocha.com.pe/wpcontent/uploads/2014/10/proyectosproductivos_Republica.pdf 